\title{
Anti-tumor Activity of IGF-1R Kinase Inhibitor PQIP in Colon Cancer
}

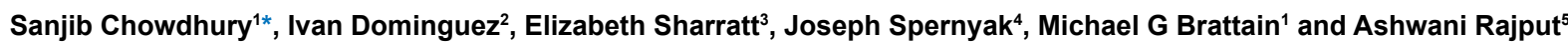

${ }^{1}$ Eppley Institute for Research in Cancer and Allied Diseases, University of Nebraska Medical Center, Omaha, Nebraska 68198-7696, USA ${ }^{2}$ Department of Surgery, State University of New York at Buffalo, Buffalo, NY 14203, USA

${ }^{3}$ Department of Pharmacology \& Therapeutics, Roswell Park Cancer Institute, Buffalo, New York 14263, USA

${ }^{4}$ Department of Cancer Biology, Roswell Park Cancer Institute, Buffalo, NY 14263, USA

${ }^{5}$ Division of Surgical Oncology, Department of Surgery, University of New Mexico Health Sciences Center, Albuquerque, NM 87131, Mexico

\begin{abstract}
Insulin-Like Growth Factors (IGFs) and their receptor, IGF-1R, are frequently expressed in human colon cancers and play important roles in promoting malignancy. We demonstrate that colon cancer cells show dependence upon an IGF2/IGF-1R autocrine loop and have characterized the effects of an IGF1R kinase inhibitor (designated PQIP in vitro and in vivo). PQIP abrogated IGF-1R mediated activation of IRS-1/Akt to inhibit survival signaling and induce apoptosis. Furthermore, PQIP inhibited mitogenesis and anchorage-independent growth in soft agarose at concentrations consistent with inhibition of IGF-1R phosphorylation. Thus, PQIP showed potent in vitro antitumor activity in colon cancer cells. The effects of PQIP on the growth of orthotopically implanted GEO colon cancer xenografts were determined following daily treatment with $75 \mathrm{mg} / \mathrm{Kg}$ of drug by oral gavage. Decreased tumor burden in BALB/c nude mice without significant weight loss and toxicity was observed. Fluorescence intensity of the GFP labeled tumors was 3 -fold higher in control mice than in treated mice. MRI analysis showed a 5-fold decrease tumor volume in treated mice. TUNEL analysis of treated and sham treated tumors indicated an 8-fold higher rate of apoptosis in PQIP treated tumors. Western blot analysis of the treated tissue samples showed inhibition of IGF1R activation and Akt signaling relative to sham treated animals. Therefore, PQIP represents an attractive therapeutic candidate for targeting IGF1Rdependent colon cancer.
\end{abstract}

\begin{abstract}
Abbreviations: IGF: Insulin-Like Growth Factor; IGF1R: IGF1 Receptor; PI-3 Kinase: Phosphatidylinositol 3 Kinase; ErbB: Protein Tyrosine Kinases Rlated to the Epidermal Growth Factor Receptor; PARP: Poly ADP Ribose Polymerase; Akt: Protein Kinase B; PDK1: 3-Phosphoinositide-Dependent Protein Kinase-1; Erk: ExtracellularResponse Kinase; MAP: Mitogen-Activated Protein; MAPK: MAP Kinase; PBS: Phosphate-Buffered Saline
\end{abstract}

\section{Introduction}

The aberrant expression of the Insulin-Like Growth Factor-1 (IGF1) and -2 (IGF2) has been implicated in a variety of tumor systems including colon cancer $[1,2]$. These oncogenic effects are mainly due to the mitogenic and antiapoptotic properties regulated by their type I tyrosine kinase receptor, the IGF1R [3]. The tyrosine kinase receptor IGF1R is the major receptor for both IGF1 and IGF2 and consists of two $\alpha$ and two $\beta$ subunits [4]. The extracellular $\alpha$ subunit contains a cysteine-rich domain responsible for ligand binding, whereas the $\beta$ subunit has a highly hydrophobic transmembrane domain and a cytoplasmic tyrosine kinase domain [4,5]. Upon ligand binding, the intrinsic tyrosine kinase activity of IGF1R is activated. This increased activity subsequently results in $\beta$ subunit autophosphorylation and triggers downstream signaling that includes the PI-3K/Akt and Ras/ MAPK pathways [6]. Activation of the IGF1R plays an important role in the regulation of cellular proliferation, transformation and survival $[7,8]$. The IGF system, including IGF1R and IGF2 is highly expressed and biologically active in many neoplastic processes [9-12]. Colon cancer is an example of a type of tumor in which IGF1R is frequently overexpressed [13,14], and a correlation between the IGF1/2 expression levels and tumor progression has been consistently documented [1418]. Thus, IGF signaling in colon cancer appears to have potential as a target for cancer therapy.

The IGF system has been extensively studied, and various approaches have been developed to downregulatethe IGF1R pathway. More recently, the successful application of small molecular weight tyrosine kinase inhibitors has sparked interest in the development of drugs that effectively target the IGF1R [2,19-23]. These small molecule inhibitors have high selectivity, are relatively inexpensive and orally active. However, several of these previously developed IGF1R antagonists were characterized using target cells engineered for ectopic overexpression of IGF1R as a target $[20,21]$. In this work, we demonstrate the effect of the ATP site IGF1R antagonists with a native cancer cell line, and extensively studied in vivo effects of the compounds in an orthotopic tumor model.PQIPis apotent inhibitor against IGF1R [24-27]. It potently inhibits human IGF1R with 14-fold selectivity over human IR in intact cells [28].

We demonstrate that the GEO human colon cancer cell line has an IGF2/IGF1R autocrine loop leading to constitutive activation of downstream signaling pathways and thus provides a convenient model for characterizing the effects of small kinase inhibitors against IGF1R. We show that PQIP disrupts abnormal IGF1R signaling in GEO cells resulting in the induction of cell death. Besides potent in vitro antitumor activity in colon cancer cells, the effects of PQIP on the growth of orthotopically implanted GEO colon cancer cells were determined. Studies with orthotopic colon carcinoma animal models in vivo showed antitumor activity without significant weight loss and toxicity. These results suggest that this small IGF1R kinase inhibitor may effectively inhibit colon cancer growth and is of potential importance in antitumor therapeutic development.

*Corresponding author: Sanjib Chowdhury, Eppley Institute for Research in Cancer and Allied Diseases, University of Nebraska Medical Center, Omaha, Nebraska 68198-7696, USA, Tel: 402-559-5570; Fax: 402-559-4651; E-mail: schowdhury@unmc.edu

Received April 27, 2013; Accepted May 30, 2013; Published June 04, 2013

Citation: Chowdhury S, Dominguez I, Sharratt E, Spernyak J, Brattain MG, et al. (2013) Anti-tumor Activity of IGF-1R Kinase Inhibitor PQIP in Colon Cancer. Clin Exp Pharmacol S4: 005. doi:10.4172/2161-1459.S4-005

Copyright: () 2013 Chowdhury S, et al. This is an open-access article distributed under the terms of the Creative Commons Attribution License, which permits unrestricted use, distribution, and reproduction in any medium, provided the original author and source are credited. 


\section{Materials and Methods}

\section{Cell culture}

The GEO human colon carcinoma cell line [29-31] was continuously maintained in a chemically defined serum-free medium. The standard maintenance medium (designated "SF") consisted of McCoy's 5A medium (Sigma, St. Louis, MO) supplemented with pyruvate, vitamins, amino acids, antibiotics, insulin (20 $\mu \mathrm{g} / \mathrm{ml}$, Sigma), transferrin ( $4 \mu \mathrm{g} / \mathrm{ml}$, Sigma) and epidermal growth factor (EGF) $(10$ ng/ml, R\&D Systems, Minneapolis, MN). Supplemented McCoy's medium (designated "SM") is McCoy's 5A medium without any exogenous growth factors. At $80 \%$ confluence, cells were changed from SF to SM medium to induce growth arrest and quiescence. Quiescence was previously operationally defined as stable minimal steady state ${ }^{3} \mathrm{H}$ thymidine incorporation. This required 3-5 days exposure to medium without growth factors (SM medium). Growth arrested cells were then treated for 24 hours with PQIP $(1 \mu \mathrm{M})$ prior to collection of cell lysates.

Antibodies: Anti-phospho-IGF1R antibody was obtained from Calbiochem. Anti-IGF1R $\beta$, anti-Erk and anti-p-Erk antibodies were from Santa Cruz Biotechnology. Anti-p-IRS-1 was from Biosource (Camarillo, CA). Anti-p-Akt Ser473, anti-Akt, anti-PARP antibodies were from Cell Signaling Technology, Inc. Anti-actin was from Sigma.

Western blot analysis: This experiment was carried as described previously(30) . Briefly, GEO cells were washed twice with cold PBS and harvested in TNESV lysis buffer (50 mMTris (pH 7.4), $100 \mathrm{mM}$ $\mathrm{NaCl}, 1 \% \mathrm{NP}-40,2 \mathrm{mM}$ EDTA, 0.1\% SDS, $50 \mathrm{mM} \mathrm{NaF}, 10 \mathrm{mM} \mathrm{Na}_{3} \mathrm{VO}_{4}$, $1 \mathrm{mM}$ PMSF, $25 \mu \mathrm{g} / \mathrm{ml} \beta$-glycerophosphate and one protease inhibitor cocktail tablet from Roche). $100 \mu \mathrm{g}$ of total protein was subjected to SDS-PAGE (7.5\% acrylamide for all proteins) and electroblotted onto Hybond ECL nitrocellulose membranes (Amersham, Arlington Heights, IL). The membranes were blocked in TTBS buffer $(20 \mathrm{mM}$ Tris ( $\mathrm{pH}$ 7.5), $500 \mathrm{mM} \mathrm{NaCl}, 0.05 \%$ Tween-20) containing 5\% nonfat dried milk for 1 hour at room temperature followed by incubation with primary antibody overnight at $4^{\circ} \mathrm{C}$. The blots were labeled with peroxidase conjugated AffiniPure goat anti-mouse or anti-rabbit IgG (Jackson ImmunoResearch Laboratories, Inc.) for 1 hour and the protein was detected using an Enhanced Chemiluminescence (ECL) method according to the manufacturer's instructions (Amersham).

Quantitative PCR: RNA was collected from the appropriate cells using the QIAGEN RNeasy Mini-Kit (QIAGEN, Valencia, CA). A reverse transcriptase reaction was then performed on the RNA and quantitative PCR was used to analyze the samples using the Taqman gene expression system following the manufacturer's instructions (Applied Biosystems, Foster city, CA). The IGF1, IGF2 and IGF1R primer-probe mixes were purchased from Applied Biosystems, and GAPDH-JOE probe was used as an endogenous control.

\section{DNA Fragmentation Assay (Cell Death Detection ELISA)}

Cells were plated at a density of 8,000 cells per well in SF medium in 96-well plates, and allowed to attach overnight at $37^{\circ} \mathrm{C}$. Media were changed 24 hours later and cells were treated to varying concentrations of PQIP or LY294002 for another 72 hours at $37^{\circ} \mathrm{C}$. The Roche Cell Death Detection ELISA kit according to the manufacturer's instructions (Roche, Germany) detected DNA fragmentation.

Anchorage-independent growth: Soft agarose assays were performed as described previously [29]. Briefly, 25,000 cells resuspended in $0.4 \%$ low melting point agarose (Sigma) were plated on a $0.8 \%$ agaroseunderlayer in a 6 -well plate in triplicate. Both layers contained PQIP treatment $(0.1 \mu \mathrm{M}$ and $1 \mu \mathrm{M})$ in SF medium. Colonies were allowed to grow for 2 weeks at $37^{\circ} \mathrm{C}$ in a humidified incubator at $5 \% \mathrm{CO}_{2}$, stained with $1 \mathrm{ml}$ of p-iodonitrotetrazolium violet (Sigma) overnight, and photographed.

\section{Animals}

Male athymic BALB/c nude mice between 4-6 weeks of age were acquired from the National Cancer Institute (NCI). Housing for these animals was maintained in a HEPA-filtrated environment within sterilized cages. All animals were subjected to a daily $12 \mathrm{hr}$ light/12-hr dark cycle. All animal procedures were conductedwith approval of and in compliance with the Roswell Park Cancer Institute's Institutional Animal Care and Use Committee (IACUC).

\section{Subcutaneous Tumor Xenograft and Surgical Orthotopic Implantation (SOI)}

GEO GFP labeled cells were harvested using a trypsin 0.125\% degradation assay (Cellgro, Herndnon, VA), counted and seven million cells suspended in a volume of $0.2 \mathrm{ml}$ SF medium. These samples were injected subcutaneously at the right flank in 5-6 weeks old male $\mathrm{BALB} / \mathrm{c}$ nude mice. Growth curves were generated by external, twodimensional measurements carried out three times per week using an electronic caliper. Tumor volume was determined by the equation volume $=3.14\left(\right.$ length $\left.\times(\text { width })^{2}\right) / 6$. Once tumor volume reached a minimum of $500 \mathrm{~mm}^{3}$, the animal was euthanized and tumor was harvested. Xenografts were imaged under fluorescent light to confirm tumor viability. Tumor areas expressing GFP were minced in $1 \mathrm{~mm}^{3}$ pieces and maintained in Earl's Minimal Essential Medium (MEM) until subsequent orthotopic implantation.

Surgical Orthotopic Implantation (SOI): Under sterile technique, twenty male $\mathrm{BALB} / \mathrm{c}$ mice were anesthetized with inhaled isoflurane (SurgiVet) and the abdomen was prepped with betadine antiseptic. Perioperatively, the animals were injected subcutaneously with $1 \mathrm{ml}$ of sterile normal saline and $0.1 \mathrm{ml}$ of buprenorphine hydrochloride for fluid replacement and analgesia respectively. Using microsurgical techniques, a one centimeter left paramedian vertical incision was made and the cecum and ascending colon were eviscerated. The serosal layer was disrupted using microforcepsand two pieces of tumor xenograft were implanted in the cecum and ascending colon respectively. The xenograft was secured to the large intestine using 8-0 nylon suture, the colon was returned to the peritoneal cavity and the abdominal wall approximated using 5-0 vicryl suture. Post-implantation, the animals were isolated in separate cages for 24 hours. After this period of observation, the animals were returned to their normal environment. Seven days after implantation, the animals were divided equally into control and treatment groups. PQIP treatment $(75 \mathrm{mg} / \mathrm{Kg}$ in $25 \mathrm{mM}$ tartaric acid vehicle) and vehicle alone were administered by oral gavage as indicated. Animals were euthanized 21 days after treatment started for further analysis.

\section{GFP imaging, histology, TUNEL and Ki-67 analysis}

Serial weekly whole body imaging was performed in a light box (Lightools Research, Encinitas, CA) with a LT-9Macroimsys Retiga Ex Camera with filter sets for GFP of $470 \mathrm{~nm}$ excitation and 515 emissions. GFP imaging facilitated the assessment of primary tumor growth. Animals were euthanized and necropsied. At necropsy, the primary tumor(s) was imaged using GFP to verify primary tumor viability and qualitative measurement. Histology Techniques: During necropsy, primary tumor and colon was harvested. Portions of the tissues were placed in $10 \%$ formalin solution for 24 hours or were dissected and 
flash frozen individually in dry ice/ethanol bath. Tissues were then processed and embedded in paraffin. Slides were cutfor H\&E staining. Apotag (Oncor, Gaithersburg, MD) terminal nucleotidyl TransferaseMediated Nick End Labeling (TUNEL) assay kits were used to generate in vivo apoptosisrates. Rates were determined by counting the number of positively stained nuclei in 3 random histological sections in a $75 \mu \mathrm{m}^{2}$ field at 20x magnification. The proliferation rates were determined by Ki-67 staining (Dako Corporation) semi-quantitatively as previously described [30].

\section{Magnetic resonance imaging (MRI) analysis}

MR imaging was carried out on a 4.7 Tesla, $33 \mathrm{~cm}$ horizontal bore MR magnet (GE NMR Instruments, Fremont, CA) incorporating AVANCE digital electronics (BrukerBioSpec platform with ParaVision ${ }^{\circ}$ Version 3.0.2 Operating System, Bruker Medical, Billerica, MA). Prior to all MR imaging, each animal was injected with $0.3 \mathrm{mmol} / \mathrm{kg}$ of $\mathrm{MR}$ contrast agent (Magnevist', Bayer Healthcare, Montville, NJ) to aid in detection of primary tumors.

Mice were screened for the detection of primary tumors utilizing a $35 \mathrm{~mm}$ radiofrequency coil. Coronal, $\mathrm{T} 2$-weighted $\left(\mathrm{TE}_{\text {eff }} / \mathrm{TR}=40 / 2500\right.$ $\mathrm{ms}$, echo train length $=8$ ) fast spin echo scans were acquired with the following pertinent MR imaging parameters: averages $=8$, field of view $=4.8 \times 3.2 \mathrm{~cm}$, matrix $=256 \times 192$, slice thickness $=1 \mathrm{~mm}$, slices $=15$. Tumor volumes were calculated by manually drawing regions of interest (ROI's) over the tumors and calculating volumes in commercially available medical imaging processing software (Analyze 7.0, AnalyzeDirect, Overland Park, KS).

\section{Results}

\section{GEO cells demonstrate constitutive IGF1R activation}

Quantitative PCR analysis showed IGF-2 and IGF1R mRNAs were expressed in GEO cells (Figures 1A-1B), but IGF-1 was not detectable under the same conditions (data not shown). Western blot analysis showed high levels of both IGF1R total protein and phospho-IGF1R in confluent cells and detectable activation of IGF1R after 5 days after removal of growth factors from the medium (Figure 1C). These results confirmed an active IGF-2/IGF1R autocrine loop in GEO cells [28].

\section{In vitro inhibition of IGF1R signaling by the selective IGF1R kinase inhibitor PQIP}

The GEO cell line was used to characterize the effect of a small kinase inhibitor against IGF1R designated PQIP. The selectivity of PQIP against the highly homologous insulin receptor was found to be 14-fold [28]. The effects of PQIP treatment on receptor phosphorylation and downstream signaling were assessed as a function of constitutive activation following growth factor deprivation in serum free, growth factor free medium (SM) for 5 days as described under "Materials and Methods". PQIP effectively inhibited phosphorylation of IGF1R as well as downstream phosphorylation of IRS-1 and Akt (Figure 2A). However, other downstream targets, such as phospho-Erk (Figure 2A), phospho-Src, or phospho-PLC $\gamma$ (data not shown) were not affected; indicating PQIP selectively abrogated the p-IGF1R/p-IRS-1/p-Akt pathway in GEO cells. Since IGF1R/Akt signaling has been linked to survival signaling in many types of cancer cells [32-35], we analyzed the ability of PQIP to induce apoptosis in GEO cells. PARP cleavage was increased by treatment with $1 \mu \mathrm{M}$ of PQIP (Figure 2A). Determination of DNA fragmentation confirmed that PQIP induces apoptosis (Figure 2A). GEO cells were treated with LY294002, a well-known PI-3 kinase inhibitor to determine whether the PI-3 kinase pathway is directly linked to apoptosis. This compound inhibited phospho-PDK1 and phospho-Akt but not phospho-Erk, and effectively induced apoptosis as shown in figure $2 \mathrm{~B}$, thus confirming that inappropriate constitutive IGF1R activation in turn leads to constitutive PI-3 kinase/Akt pathway activation that is critical in sustaining survival signals in GEO cells.

\section{In vitro antitumor activity of the compounds}

We also assessed the in vitro functional impact of PQIP in GEO colon cancer cells by evaluating the degree to which inhibition of IGF1R

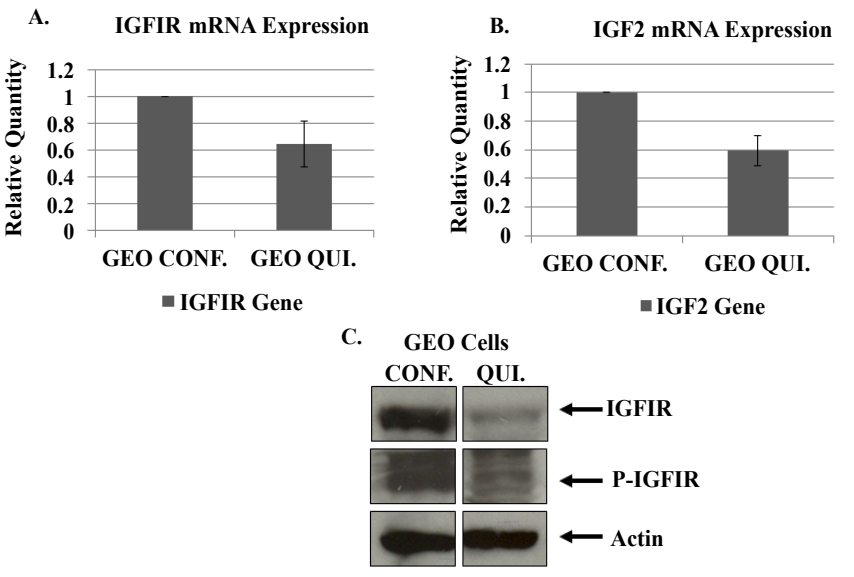

Figure 1: Demonstration ofautocrine IGF2/IGF1R activity in GEO colon cancer cells. $A-B$ : RNA was collected from confluent (CONF.) or quiescent day 5 (QUI.) GEO cells and a two-step reverse transcription-PCR procedure were performed. Linear data normalized to the level of confluent GEO (GEO CONF.) cells from either IGF1R or IGF2 quantitative PCR (mean \pm S.E.M.; $\mathrm{n}=3$ ). GAPDH- JOE probe was used as an endogenous control. C: Confluent and quiescent GEO cells were harvested and subjected to western blot analysis. The blots were probed with phospho-IGF1R, IGF1R and actin (as a loading control) antibodies.
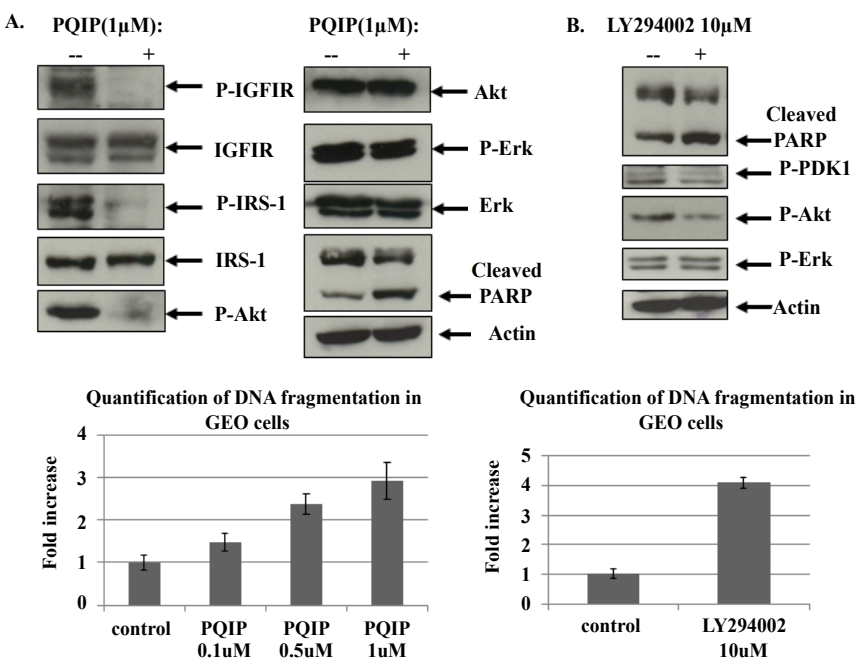

Figure 2: PQIP inhibits IGF1R signaling and induces apoptosis. Quiescent GEO cells were treated with $1 \mu \mathrm{M}$ PQIP $(A)$ or $10 \mu \mathrm{M}$ LY294002 $(B)$ for 24 hours, whole cell lysates were resolved by SDS-PAGE, and immunoblotted with different antibodies as indicated. Anti-actin polyclonal antibody was used as a loading control. GEO cells were seeded at 8,000 cells/well in 96-well plates and allowed to adhere overnight. The next day, cells were treated with different concentrations of either PQIP $(A)$, or LY294002 (B). DNA fragmentation assay was performed and absorbance was measured at 405 $\mathrm{nm}$ (mean \pm s.d.; $\mathrm{n}=3$ ). 
activation can suppress the anchorage independent growth. Anchorage independent growth is considered to be reflective of malignancy [36]. Consequently, we determined the ability of the compounds to inhibit colony formation in soft agarose. Treatment of GEO cells by PQIP almost completely blocked the anchorage independent growth of GEO cells in soft agarose. Thus, taken together with the in vitro data indicate strong potential for PQIP as targeting agents for therapy of tumors dependent upon IGF1R signaling.

\section{In vivo characterization of the IGF1R inhibitor in an orthotopic model of colon cancer}

GEO xenografts have been extensively utilized as an in vivo model for targeting by signal transduction inhibitors $[37,38]$. Recently, studies have suggested that animal models using orthotopically implanted tumors are more predictive of responses than ectopic tumors [39-41]. We have established an orthotopic model of colon cancer [30, 40-44]. Consequently, we interrogated GEO orthotopic implants for response to PQIP in vivo. GFP-labeled GEO cells were injected subcutaneously into $\mathrm{BALB} / \mathrm{c}$ nude mice. Once the subcutaneous xenografts were established, they were minced in tissue culture medium and $1 \mathrm{~mm}^{3}$ fragments were subserosally implanted onto the colons of other $\mathrm{BALB} / \mathrm{c}$ nude mice. Seven days after implantation, treatment with PQIP was carried out using tartaric acid as the vehicle with once daily dosing of the drug $(75 \mathrm{mg} / \mathrm{Kg})$ by oral gavage for 21 consecutive days. Less than $10 \%$ loss of body weight was observed in the in vivo study (data not shown). PQIP significantly reduced the fluorescence intensity of the GFP-labeled tumors in treated mice as compared to control mice (Figure 3A). Quantification of the fluorescent tumor area showed a 3-fold decrease in treated mice (Figure 3B). Since our in vitro data indicated, PQIP effectively inhibited the IGF1R/IRS1/Akt signaling pathway we tested the inhibitory effects of PQIP on the same pathway in tumor tissues as well. As seen in Figure 4C, western blot analysis of the treated tissue samples showed inhibition of all IGF1R activation, majority of IRS1 phosphorylation and Akt signaling relative to sham treated animals. The fact that a few samples showed relative resistance to PQIP in downstream signaling components implies that IRS-1 might be regulated by other receptors and Akt signaling might escape the inhibition effect by IGF1R inhibitor in an unknown manner.

We also utilized MRI imaging [45-47] to visualize changes in the size of PQIP treated tumors relative to controls. The results were consistent with those obtained from GFP imaging as quantification of the MRI results showed a 5-fold decrease of tumor volume (Figure 4). A TUNEL assay was performed to investigate the mechanism of decreased tumor burden in PQIP treated animals. We found that the shrinking of primary tumor burden is apoptotic in vivo (Figure 5A). This is consistent with the in vitro observation that abrogation of IGF1R mediated activation of IRS1/Akt by PQIP induced apoptosis. Quantification of the TUNEL assay of treated and sham treated tumors indicated an 8-fold higher rate in PQIP treated tumors (Figure 5B). Taken together, these results indicated that PQIP inhibits GEO tumor growth by downregulating IGF1R and PI3K signaling in vivo.

\section{Discussion}

Prior studies have indicated that IGF1R activation plays an important role in the malignancy of many tumor types $[2,3,13]$. Knockdown of IGF1R function has been found to interfere with tumor growth in a number of models [34, 48-51]. Small molecule kinase inhibitors which target the IGF1R have recently been described $[2,20,21]$. The activity of these inhibitors, however, was characterized against IGF1R dependent engineered cells rather than human cancer cell lines. Furthermore, these studies characterized drug effects on subcutaneous xenografts rather than models that more correctly reflect the natural tumor environment [28]. This study characterized the antitumor activity of a small molecule IGF1R kinase inhibitor, PQIP in an orthotopic human colon cancer xenograft model. The inhibitor blocked IGF1R phosphorylation, induced apoptosis through the inhibition of inappropriate PI3K signaling linked to constitutive

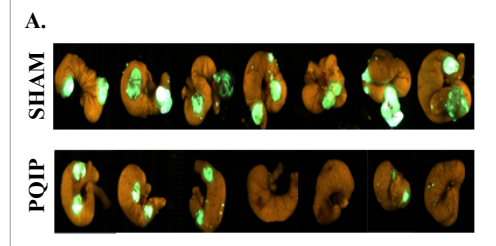

B. GEO Tx Primary with PQIP (21days)

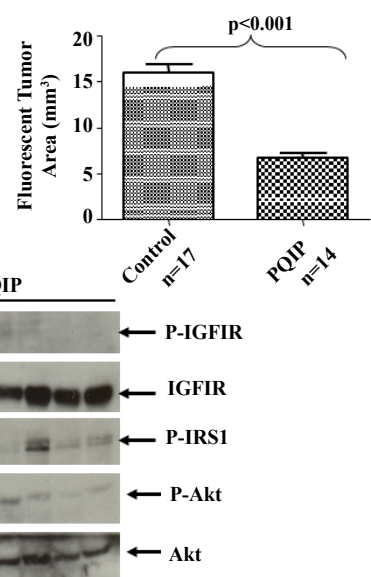

Figure 3: The effects of PQIP on the growth of orthotopically implanted GEO colon cancer cells. A: GEO cells were labeled with GFP and injected s.c. into athymic nude mice. Tumor xenografts were implanted and PQIP treatment was carried as described above. Photographs show representative examples of GFP imaging results of the explanted colon. B: Quantification of the fluorescent tumor area $\left(\mathrm{mm}^{3}\right)$ of PQIP treated and sham treated animals.C: Western blot analysis of IGF1R, IRS1, Akt phosphorylation and total protein contents in orthotopic implanted tumor tissues (shown are representative examples) after oral treatment with PQIP for 21 days $(75 \mathrm{mg} / \mathrm{Kg} / \mathrm{day})$ as described.

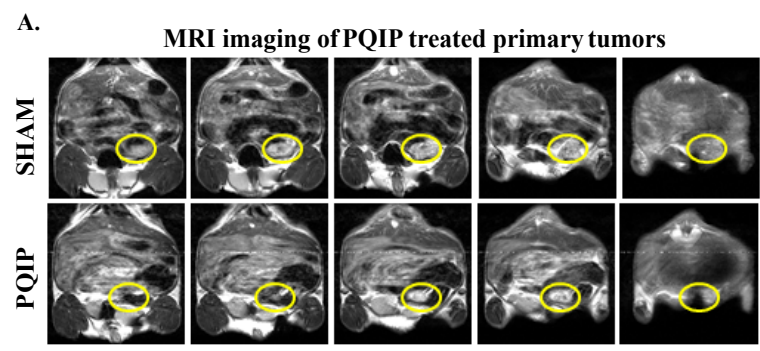

B. GEO Tx Primary with PQIPAverage Tumor Volume (MRI)

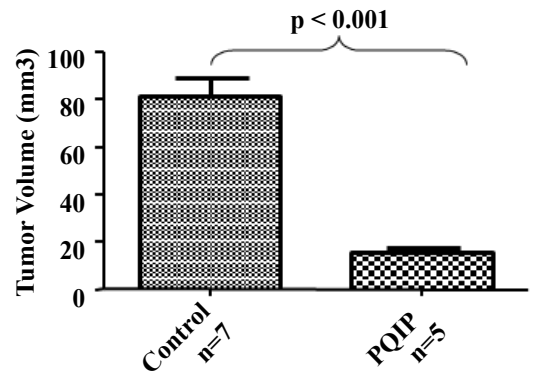

Figure 4: MRI imaging of PQIP treated primary tumors. A: MRI imaging of PQIP treated and sham treated tumors. Representative examples of MRI imaging results are shown. $B$ : Volumetric assessment of tumor by MRI of treated and untreated animals demonstrates decreased tumor volume in animals treated with PQIP. 

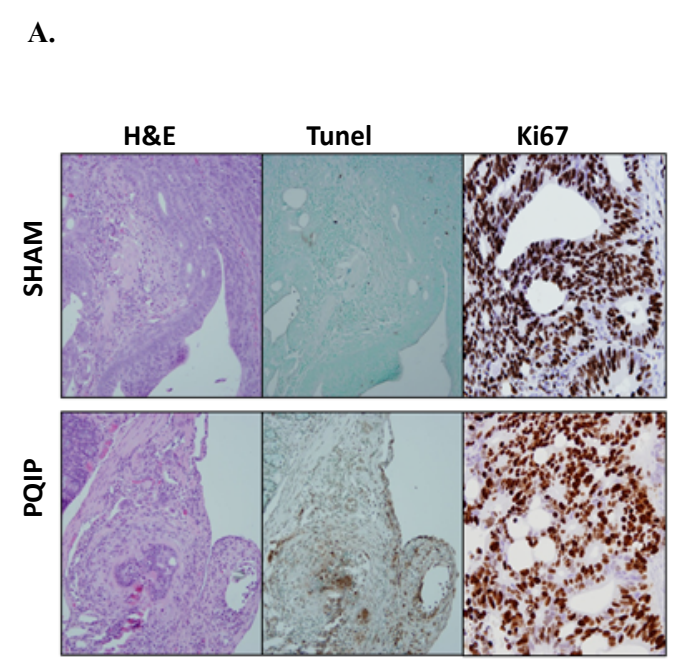

B.
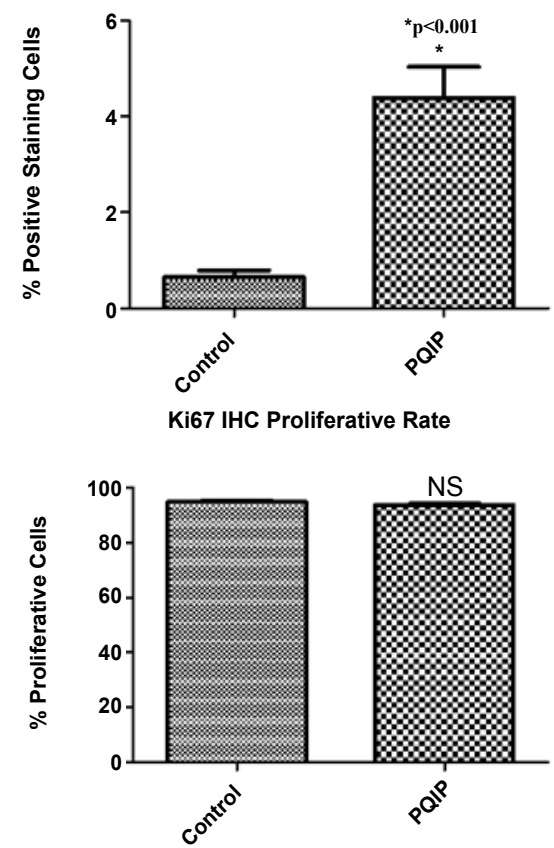

Figure 5: Increased apoptosis in PQIP treated tumor tissues. BALB/c nude mice orthotopically implanted with GEO were treated on days 8-30 post-implantation with either $75 \mathrm{mg} / \mathrm{kg}$ PQIP or vehicle control by oral gavage. At necropsy, tissues were formalin fixed and paraffin embedded for H\&E staining and IHC. A: Apotag TUNEL assay (Oncor) demonstrates increased numbers of apoptotic cells in tumors treated with PQIP compared to control animals. Representative examples of H\&E staining and TUNEL assays are shown. $B$ : The apoptotic rate of control and PQIP treated tumor samples was determined by counting positive nuclei in three random $75 \mu m^{2}$ fields at 20x magnification whereas proliferation on ki67 assays was equivalent.

IGF1R activation. More importantly, determination of the in vivo mechanism of PQIP on colon cancer growth at the orthotopic site by GEO colon cancer cells showed that the mechanism of action of these small molecule inhibitors was associated with blockade of the PI3K/ Akt pathway. The inhibition of cell survival as determined by TUNEL staining was a result of apoptosis, but the change in cancer cell survival was not associated with changes in Ki67 staining.

Clinical correlation between IGF1R activation and poorer outcome has been reported in different tumor types including colon cancer $[13,52,53]$. Colon cancer has been shown to display aberrant expression of IGF1R autocrine activity. IGF2 has been observed in the autocrine growth stimulation of human colon tumor growth, and IGF2/IGF1R autocrine activity appears to be a common growth mechanism in colon carcinogenesis $[49,54]$. We have shown that GEO cells have an IGF2/ IGF1R autocrine loop (Figure 1) that imparts the cells with constitutive cell survival signaling through the PI3K pathway under growth factor deprivation stress conditions in vitro. Thus, the GEO colon cancer cell line appears to be a valuable cell model for development of IGF1R inhibitors.

Our studies demonstrated that the treatment of constitutively activated IGF1R with IGF1R antagonists inhibits mitogenesis/ proliferation and induces apoptosis. Mitsiades et al. [21] found that in engineered cells exposed to IGF1 or serum, IGF1R inhibition led to decreased expression of genes implicated in proliferation, decreased $\mathrm{Rb}$ phosphorylation and suppression of multiple genes involved in DNA synthesis. These data are consistent with our finding that PQIP inhibits initiation of DNA synthesis via IGF1R inhibition when growth arrested GEO cells are stimulated to re-enter the cell cycle. Moreover, our observation that PQIP specifically inhibit the IGF1R/IRS-1/Akt pathway to induce apoptosis provides the identification of a specific signaling pathway which is critical for inhibition in order to obtain induction of apoptosis in contrast to the broad effects shown in the previous studies [20,21].

Experience with targeted therapies has indicated that response rates to single agents are in general very low. Thus, a key aspect in the development of this approach is to identify subsets of patients who are likely to show the greatest benefit from the inhibition of a particular molecular target. It has been reported that both the Erk/MAPK and PI-3K/Akt pathways are involved in the enhancement of malignant effects by IGF1R in colorectal carcinoma $[1,33,49,55]$. However, the two pathways are not always activated simultaneously downstream of the IGF1R signaling [49]. Our results indicated that PQIP inhibits the IGF1R/PI3K/Akt pathway, but not the Erk/MAPK pathway in GEO cells. Other prominent downstream signaling pathways, such as the PLC $\gamma$ and Src pathways, are not inhibited by PQIP, suggesting the IGF1R-Akt axis is the selective target for IGF1R antagonist in these cells and this was consistent with Western data from the primary tumors in vivo. Thus, IGF1R appears to preferentially activate the PI-3K/Akt pathway in GEO colon cancer cells. This selectivity of the IGF1R in these cells suggests that patients in whom the IGF1R preferentially activates the PI3K pathway for cell survival and is not strongly linked to other survival pathways may identify a sensitive subset of patients for effective IGF1R antagonism. The mechanism of the selective effect of PQIP in GEO cells is not clear. GEO cells have autocrine loops involving the ErbB family receptors as well as the IGF1R autocrine loop described here [56-58]. These may be primarily responsible for the activation of other pathways as they have been linked to Erk activation in GEO cells $[57,59]$. 
Clinical observations have suggested that the specific organ environment can influence the response of tumors to therapeutic strategies [60]. Anti-cancer drugs are commonly screened using panels of human tumor xenografts implanted subcutaneously in nude mice. However, subcutaneous tumor models are not generally representative of the microenvironment of the primary tumor site in patients [61]. Thus, orthotopic tumor models have an advantage for reflecting to microenvironment's effects on tumor growth characteristics and their response to drug treatment [62]. We have successfully developed an orthotopic animal model for colon cancer as demonstrated in our prior studies $[30,43,44]$. This in vivo pre-clinical model using small molecule inhibitor PQIP demonstrates the potential importance of targeting IGF1R in human colon cancer.

\section{Acknowledgements}

We would like to thank Yi Peter Hu, Ph.D. for his help with the research.

\section{References}

1. Reinmuth N, Liu W, Fan F, Jung YD, Ahmad SA, et al. (2002) Blockade of insulin-like growth factor I receptor function inhibits growth and angiogenesis of colon cancer. Clin Cancer Res 8: 3259-3269.

2. Arnaldez FI, Helman LJ (2012) Targeting the insulin growth factor receptor 1. Hematol Oncol Clin North Am 26: 527-542, vii-viii.

3. LeRoith D, Roberts CT Jr (2003) The insulin-like growth factor system and cancer. Cancer Lett 195: 127-137.

4. Baserga R, Hongo A, Rubini M, Prisco M, Valentinis B (1997) The IGF-I receptor in cell growth, transformation and apoptosis. Biochim Biophys Acta 1332: F105-126.

5. Werner H, Le Roith D (1997) The insulin-like growth factor-I receptor signaling pathways are important for tumorigenesis and inhibition of apoptosis. Crit Rev Oncog 8: 71-92.

6. De Meyts $P(2004)$ Insulin and its receptor: structure, function and evolution. Bioessays 26: 1351-1362.

7. Baserga $R$ (2000) The contradictions of the insulin-like growth factor 1 receptor Oncogene 19: 5574-5581.

8. Wang $Y$, Sun $Y(2002)$ Insulin-like growth factor receptor-1 as an anti-cancer target: blocking transformation and inducing apoptosis. Curr Cancer Drug Targets 2: 191-207.

9. LeRoith D, Helman L (2004) The new kid on the block(ade) of the IGF-1 receptor. Cancer Cell 5: 201-202.

10. Werner H, LeRoith $D$ (1996) The role of the insulin-like growth factor system in human cancer. Adv Cancer Res 68: 183-223.

11. Kim SY, Wan X, Helman LJ (2009) Targeting IGF-1R in the treatment of sarcomas: past, present and future. Bull Cancer 96: E52-60.

12. Law JH, Habibi G, Hu K, Masoudi H, Wang MY, et al. (2008) Phosphorylated insulin-like growth factor-i/insulin receptor is present in all breast cancer subtypes and is related to poor survival. Cancer Res 68: 10238-10246.

13. Hakam A, Yeatman TJ, Lu L, Mora L, Marcet G, et al. (1999) Expression of insulin-like growth factor-1 receptor in human colorectal cancer. Hum Pathol 30: $1128-1133$

14. Freier S, Weiss O, Eran M, Flyvbjerg A, Dahan R, et al. (1999) Expression of the insulin-like growth factors and their receptors in adenocarcinoma of the colon. Gut 44: 704-708

15. Tricoli JV, Rall LB, Karakousis CP, Herrera L, Petrelli NJ, et al. (1986) Enhanced levels of insulin-like growth factor messenger RNA in human colon carcinomas and liposarcomas. Cancer Res 46: 6169-6173.

16. Lambert S, Vivario J, Boniver J, Gol-Winkler R (1990) Abnormal expression and structural modification of the insulin-like growth-factor-II gene in human colorectal tumors. Int J Cancer 46: 405-410.

17. Kawamoto K, Onodera H, Kondo S, Kan S, Ikeuchi D, et al. (1998) Expression of insulin-like growth factor-2 can predict the prognosis of human colorectal cancer patients: correlation with tumor progression, proliferative activity and survival. Oncology 55: 242-248.
18. Li SR, Ng CF, Banerjea A, Ahmed S, Hands R, et al. (2004) Differential expression patterns of the insulin-like growth factor 2 gene in human colorectal cancer. Tumour Biol 25: 62-68.

19. Blum G, Gazit A, Levitzki A (2000) Substrate competitive inhibitors of IGF-1 receptor kinase. Biochemistry 39:15705-15712.

20. García-Echeverría C, Pearson MA, Marti A, Meyer T, Mestan J, et al. (2004) In vivo antitumor activity of NVP-AEW541-A novel, potent, and selective inhibitor of the IGF-IR kinase. Cancer Cell 5: 231-239.

21. Mitsiades CS, Mitsiades NS, McMullan CJ, Poulaki V, Shringarpure R, et al. (2004) Inhibition of the insulin-like growth factor receptor-1 tyrosine kinase activity as a therapeutic strategy for multiple myeloma, other hematologic malignancies, and solid tumors. Cancer Cell 5: 221-230.

22. Bell IM, Stirdivant SM, Ahern J, Culberson JC, Darke PL, et al. (2005) Biochemical and structural characterization of a novel class of inhibitors of the type 1 insulin-like growth factor and insulin receptor kinases. Biochemistry 44 9430-9440.

23. Scotlandi K, Manara MC, Nicoletti G, Lollini PL, Lukas S, et al. (2005) Antitumor activity of the insulin-like growth factor-I receptor kinase inhibitor NVP-AEW541 in musculoskeletal tumors. Cancer Res 65: 3868-3876.

24. Khatri A, Brundage RC, Hull JM, Williams BW, Yee D, et al. (2012) Pharmacodynamic modeling of sequence-dependent antitumor activity of insulin-like growth factor blockade and gemcitabine. AAPS J 14: 1-9.

25. Kim WY, Prudkin L, Feng L, Kim ES, Hennessy B, et al. (2012) Epiderma growth factor receptor and K-Ras mutations and resistance of lung cancer to insulin-like growth factor 1 receptor tyrosine kinase inhibitors. Cancer 118 3993-4003.

26. Mulvihill MJ, Ji QS, Coate HR, Cooke A, Dong H, et al. (2008) Nove 2-phenylquinolin-7-yl-derived imidazo[1,5-a]pyrazines as potent insulin-like growth factor-I receptor (IGF-IR) inhibitors. Bioorg Med Chem 16: 1359-1375.

27. Zeng X, Zhang H, Oh A, Zhang Y, Yee D (2012) Enhancement of doxorubicin cytotoxicity of human cancer cells by tyrosine kinase inhibition of insulin receptor and type I IGF receptor. Breast Cancer Res Treat 133: 117-126.

28. Ji QS, Mulvihill MJ, Rosenfeld-Franklin M (2007) A novel, potent, and selective insulin-like growth factor-I receptor kinase inhibitor blocks insulin-like growth factor-I receptor signaling in vitro and inhibits insulin-like growth factor-I recepto dependent tumor growth in vivo. Molecular cancer therapeutics 6: 2158-2167.

29. Brattain MG, Levine AE, Chakrabarty S, Yeoman LC, Willson JK, et al. (1984) Heterogeneity of human colon carcinoma. Cancer Metastasis Rev 3: 177-191.

30. Chowdhury S, Howell GM, Rajput A, Teggart CA, Brattain LE, et al. (2011) Identification of a novel TGF ${ }^{2} / \mathrm{PKA}$ signaling transduceome in mediating control of cell survival and metastasis in colon cancer. PLoS One 6: e19335.

31. Hu YP, Patil SB, Panasiewicz M, Li W, Hauser J, et al. (2008) Heterogeneity of receptor function in colon carcinoma cells determined by cross-talk between type I insulin-like growth factor receptor and epidermal growth factor receptor. Cancer Res 68: 8004-8013.

32. Sekharam M, Zhao H, Sun M, Fang Q, Zhang Q, et al. (2003) Insulin-like growth factor 1 receptor enhances invasion and induces resistance to apoptosis of colon cancer cells through the Akt/Bcl-x(L) pathway. Cancer Res 63: 77087716.

33. Chakravarti A, Loeffler JS, Dyson NJ (2002) Insulin-like growth factor receptor mediates resistance to anti-epidermal growth factor receptor therapy in primary human glioblastoma cells through continued activation of phosphoinositide 3-kinase signaling. Cancer research 62: 200-207.

34. Scotlandi K, Avnet S, Benini S, Manara MC, Serra M, et al. (2002) Expression of an IGF-I receptor dominant negative mutant induces apoptosis, inhibits tumorigenesis and enhances chemosensitivity in Ewing's sarcoma cells. Int Cancer 101: 11-16.

35. Lee CT, Wu S, Gabrilovich D, Chen H, Nadaf-Rahrov S, et al. (1996) Antitumo effects of an adenovirus expressing antisense insulin-like growth factor I receptor on human lung cancer cell lines. Cancer Res 56: 3038-3041.

36. Jiang D, Yang H, Willson JK, Liang J, Humphrey LE, et al. (1998) Autocrine transforming growth factor alpha provides a growth advantage to malignan cells by facilitating re-entry into the cell cycle from suboptimal growth states. $J$ Biol Chem 273: 31471-31479.

37. Baselga $J$ (2001) Targeting the epidermal growth factor receptor: a clinica reality. J Clin Oncol 19: 41S-44S. 
Citation: Chowdhury S, Dominguez I, Sharratt E, Spernyak J, Brattain MG, et al. (2013) Anti-tumor Activity of IGF-1R Kinase Inhibitor PQIP in Colon Cancer. Clin Exp Pharmacol S4: 005. doi:10.4172/2161-1459.S4-005

Page 7 of 7

38. Ciardiello F, Tortora G (2001) A novel approach in the treatment of cancer: targeting the epidermal growth factor receptor. Clin Cancer Res 7: 2958-2970.

39. Fidler IJ (1991) Orthotopic implantation of human colon carcinomas into nude mice provides a valuable model for the biology and therapy of metastasis. Cancer Metastasis Rev 10: 229-243.

40. Killion JJ, Radinsky R, Fidler IJ (1998) Orthotopic models are necessary to predict therapy of transplantable tumors in mice. Cancer Metastasis Rev 17: 279-284

41. Hoffman RM (1999) Orthotopic metastatic mouse models for anticancer drug discovery and evaluation: a bridge to the clinic. Invest New Drugs 17: 343-359.

42. Guo XN, Rajput A, Rose R, Hauser J, Beko A, et al. (2007) Mutant PIK3CAbearing colon cancer cells display increased metastasis in an orthotopic model. Cancer Res 67: 5851-5858

43. Ongchin M, Sharratt E, Dominguez I, Simms N, Wang J, et al. (2009) The effects of epidermal growth factor receptor activation and attenuation of the TGFbeta pathway in an orthotopic model of colon cancer. J Surg Res 156: 250-256

44. Wang J, Rajput A, Kan JL, Rose R, Liu XQ, et al. (2009) Knockdown of Ron kinase inhibits mutant phosphatidylinositol 3-kinase and reduces metastasis in human colon carcinoma. J Biol Chem 284: 10912-10922.

45. Palmieri D, Smith QR, Lockman PR, Bronder J, Gril B, et al. (2006) Brain metastases of breast cancer. Breast Dis 26: 139-147

46. Ronen SM, Leach MO (2001) Imaging biochemistry: applications to breast cancer. Breast Cancer Res 3: 36-40.

47. Guccione S, Li KC, Bednarski MD (2004) Molecular imaging and therapy directed at the neovasculature in pathologies. How imaging can be incorporated into vascular-targeted delivery systems to generate active therapeutic agents. IEEE Eng Med Biol Mag 23: 50-56.

48. Resnicoff M, Sell C, Rubini M, Coppola D, Ambrose D, et al. (1994) Rat glioblastoma cells expressing an antisense RNA to the insulin-like growth factor-1 (IGF-1) receptor are nontumorigenic and induce regression of wildtype tumors. Cancer Res 54: 2218-2222.

49. Adachi Y, Lee CT, Coffee K, Yamagata N, Ohm JE, et al. (2002) Effects of genetic blockade of the insulin-like growth factor receptor in human colon cancer cell lines. Gastroenterology 123: 1191-1204.

50. Resnicoff M, Coppola D, Sell C, Rubin R, Ferrone S, et al. (1994) Growth inhibition of human melanoma cells in nude mice by antisense strategies to the type 1 insulin-like growth factor receptor. Cancer Res 54: 4848-4850.
51. Wang JY, Del Valle L, Gordon J, Rubini M, Romano G, et al. (2001) Activation of the IGF-IR system contributes to malignant growth of human and mouse medulloblastomas. Oncogene 20: 3857-3868.

52. All-Ericsson C, Girnita L, Seregard S, Bartolazzi A, Jager MJ, et al. (2002) Insulin-like growth factor-1 receptor in uveal melanoma: a predictor fo metastatic disease and a potential therapeutic target. Invest Ophthalmol Vis Sci 43: 1-8.

53. Turner BC, Haffty BG, Narayanan L, Yuan J, Havre PA, et al. (1997) Insulin-like growth factor-I receptor overexpression mediates cellular radioresistance and local breast cancer recurrence after lumpectomy and radiation. Cancer Res 57: 3079-3083

54. Quinn KA, Treston AM, Unsworth EJ, Miller MJ, Vos M, et al. (1996) Insulin-like growth factor expression in human cancer cell lines. J Biol Chem 271: 11477 11483.

55. Licato LL, Keku TO, Wurzelmann JI, Murray SC, Woosley JT, et al. (1997) In vivo activation of mitogen-activated protein kinases in rat intestinal neoplasia. Gastroenterology 113: 1589-1598.

56. Hu YP, Venkateswarlu S, Sergina N, Howell G, St Clair P, et al. (2005) Reorganization of ErbB family and cell survival signaling after Knock-down of ErbB2 in colon cancer cells. J Biol Chem 280: 27383-27392.

57. Venkateswarlu S, Dawson DM, St Clair P, Gupta A, Willson JK, et al. (2002) Autocrine heregulin generates growth factor independence and blocks apoptosis in colon cancer cells. Oncogene 21: 78-86.

58. Ziober BL, Willson JK, Hymphrey LE, Childress-Fields K, Brattain MG (1993) Autocrine transforming growth factor-alpha is associated with progression of transformed properties in human colon cancer cells. J Biol Chem 268: 691-698.

59. Jackson JG, St Clair P, Sliwkowski MX, Brattain MG (2004) Blockade of epidermal growth factor- or heregulin-dependent ErbB2 activation with the anti-ErbB2 monoclonal antibody $2 \mathrm{C} 4$ has divergent downstream signaling and growth effects. Cancer Res 64: 2601-2609.

60. Donelli MG, Rosso R, Garattini S (1967) Selective chemotherapy in relation to the site of tumor transplantation. Int J Cancer 2: 421-424.

61. Bibby MC (2004) Orthotopic models of cancer for preclinical drug evaluation advantages and disadvantages. Eur J Cancer 40: 852-857.

62. Talmadge JE, Singh RK, Fidler IJ, Raz A (2007) Murine models to evaluate novel and conventional therapeutic strategies for cancer. Am J Pathol 170 793-804.
This article was originally published in a special issue, Novel Developments in Immunopharmacology and Immunotoxicology handled by Editor(s). Dr. Yuliang Ma, Weill Cornell Medical College, USA 